phenomenon.' They refer, however, to only one study, and although this study showed an improvement in finger cutaneous blood flow, it showed no change in either the number or the severity of Ravnaud's attacks.: Subjective benefit has been claimed in other studies of captopril both in patients with primary Raynaud's phenomenon and in those with secondary disease, but these studies were either uncontrolled or confined to case reports." By contrast, the double blind placebo controlled study of Madsen and Hvidt did not support these claims. ${ }^{\circ}$ Furthermore, our results of a double blind placebo controlled study of enalapril showed no evidence of either objective or subjective improvement during treatment for one month.

We believe that at present there is insufficient evidence to support the use of angiotensin converting enzyme inhibitors in patients with Raynaud's phenomenon. Nevertheless, further controlled studies are required to determine whether there is a dose dependent response to these inhibitors and to resolve the disparity between the subjective and objective effects seen in some studies. K DONALDSON D G WALLER

Clinical Pharmacology Group

University of Southampton,

Southampton (ieneral Hospital.

Southampton $\mathrm{SO} 9+\mathrm{XY}$

I Cooke 1ED, Nicolaides AN. Raynaud's syndrome, Br. Hed f 1990:300:553-5. (3 March

2 Rustin .MHA, Almond NE, Beacham MJ.A, et al. The effect of captopril on cutaneous blood flow in patients with primary Raynaud's phenomenon. Brf Dermatol 1987;117:751-8.

3 Miyasaki S, Miura K, Kasai Y, Abe K, Yoshinaga K. Relief from digital vasospasm by treatment with captopril and its complete inhibition by serine proteinase inhibitors in Raynauds phenomenon. Br.Med 7 1984:284:310.

+ Tosi S, Marchesoni A. Messina K. Bellintani C, Siron G, Faravelli C. Treatment of Raynaud's phenomenon with G, Faravelli C. Treatment of Ray natud's

Trubstein ( $\mathrm{i}$, Wigger E, Trubstein R, Ludwig N1, Wilgali II. Stumpe KO. Behandlung des Ravnaud-Simtoms mit M. Stumpe KO. Behandlung des Raynaud-Sym

6 Madsen JL, Hvidt S. A randomised double-blind cross-over Iadsen $\mathrm{JL}$, Hvidt $\mathrm{S}$. A randomised double-blind cross-over
investigation of treatment of Raynaud's disease with captopril. investigation of treatment of R
L'geskr Laeger 1984;146:2695-7.

Challenor VF, Waller DG, Hayward RA, Griffin MJ, Roath OS Clinical and physiological assessment of angiotensin converting enzyme inhibition in primary Ravnaud's phenomenon. Eur $\mathcal{f}$ Clin Pharmacol 1989:36 suppl:A245

\section{Management of acute coronary occlusion during coronary angioplasty}

SIR,--Dr S Geoffrey Richardson and colleagues report their experience of management of acute coronary occlusion during coronary angioplasty, with interhospital transfer being required to permit surgical revascularisation.' Eleven patients were transferred to receive emergency coronary artery bypass surgery, and they reported no deaths in this group. They therefore concluded that coronary angioplasty may be safely performed in a hospital without on site cardiac surgical facilities.

The authors do not, however, address the question of morbidity related to myocardial infarction within this group, and in particular there are no details of how many patients with acute coronary occlusion necessitating surgical revascularisation sustained appreciable myocardial infarction despite surgery

It is prudent to say that the time from coronary occlusion to revascularisation is critical as after a certain interval non-reversible mvocardial impairment and damage occur. In a series of about 100 patients seen by one of us (CR) in our unit, where all coronary angioplasties are covered by a surgeon so that prompt on site surgical intervention can be performed in the event of acute coronary occlusion, five patients required surgical intervention. All five were transferred immediately from the catheter room to the operating theatre; four had immediate surgery, and one was delayed for an hour while the surgical team were dealing with an emergency cardiac tamponade in another patient. The electrocardiograms were reviewed postoperatively: all four patients who had immediate surgical re vascularisation for acute coronary occlusion had unchanged electrocardiograms and the patient in whom surgery was delayed developed a $Q$ wave anterior myocardial infarction.

Despite the small numbers requiring surgical intervention in this series we believe that promp and on site surgical intervention can reduce morbidity related to coronary artery occlusion during percutaneous transluminal coronary angioplasty.

R T JOHNSTON

C REEK

T J SPYT

Cardiothoracic Unit,

Groby Road Hospital

Leicester LE3 $9 Q \mathrm{QH}$

I Richardson SG, Morton P, Murtagh JG, O'Keefe DB, Murph $P$, Scott ME. Management of acute coronary occlusion during percutaneous transluminal coronary angioplasty: experience of complications in a hospital without on site facilities for cardiac surgery. Br Med f 1990:300:355-8, (10 February.

\section{Surgery and salmonella}

SIR, - We think it is important that we should comment on the leading article by $\mathrm{Mr} \mathrm{J} \mathrm{G}$ Mosley and $\mathrm{Mr} \mathrm{A} \mathrm{K}$ Chaudhuri on surgery and salmonella.' The infectious disease unit for the north west sees a considerable number of patients with non-typhoid salmonella infections and a more modest number of patients with typhoid fever. It should be recognised that surgical complications in either group are extremely rare. All large series of patients with typhoid perforations come from tropical countries. There seems to be no consensus of opinion as to the best method of treatment, and how applicable methods proposed for poorly nourished patients in the Third World are to the rare case in the United Kingdom is certainly a matter for debate.

The management of the carrier state in typhoid has been considerably improved by the introduction of newer quinolines. ${ }^{2}$ There is no guarantee that carriers will be cured by the removal of the gall bladder. It will eradicate the carrier state in three out of four cases, but this is not an operation to be undertaken lightly, and occasional deaths have been reported. The operation should be contemplated only when there are similar indications to those in non-carriers and not when the sole purpose is the eradication of the carrier state.

The authors fail to mention the diagnostic dilemma posed by patients presenting with acute right abdominal pain associated with diarrhoea. Salmonella species along with Campylobacter and Yersinia species are important causes of acute ileitis and occasionally such patients undergo operation for appendicitis. Microscopy performed on stool samples can be useful in the assessment of such cases - the presence of pus cells and red cells signifies intraluminal inflammation and suggests an infective aetiology, whereas faecal smears free of inflammatory cells suggest retroileal appendicitis.

As far as potential surgical complications of infection with non-typhoid salmonella are concerned it should be recognised that colonic dilatation may occur but will usually resolve without surgery and that perforation is extremely rare. There is no evidence that a colectomy is the only method of managing a perforation caused by salmonella. Exteriorisation of the perforation with subsequent closure and also simple closure have both been used successfully. These less radical alternatives may well be preferable in most case and have been used without causing death in our patients. Though we agree with the authors that complications caused by non-typhoid salmonell must be borne in mind, we think that it should also be recognised that local or extracolonic complications are relatively rare and the need for surgery in this group of patients is extremely unusual.

B K MANDAL

P F SCHOFIELD

Regional Department of Infectiou

Diseases and Tropical Medicine,

Manchester $11108 \mathrm{~W}^{\prime} \mathrm{R}$

1 Mosley JG, Chaudhuri AK. Surgery and salmonella. Br Med 1990;300:552-3. (3 March )

Rodriquez-Noriega R, Andrade-Villaneuve J, Amava-Tapia (i. Quinolones in the treatment of salmonella carriers. Rev Infec Dis 1989;11:S1179-87.

3 Mandal BK. Infective colitis in children. Surgery (Oxford $985: 1: 495-8$

+ Schofield PF, Mandal BK, Ironside AG. Toxic dilatation of the colon in salmonella colitis and inflammatory bowel discase. BrF Surg 1979;66:5-8.

SIR, - We think that in their leading article on the surgical complications of salmonella infection Mr J G Mosley and Mr A K Chaudhuri' have underemphasised the role of Salmonella species in causing vascular infection. While focal disease may cause chronic infection in some sites, it is all too often an acute problem when it affects the vasculature. Of all the organisms that may infect arteries, Salmonella species are the commonest and seem to have a predilection for atherosclerotic lesions, $\stackrel{2}{\text { and }}$ the vast majority of reports of vascular infections with salmonella have been of infrarenal atherosclerotic aortic aneurysms. ${ }^{3}$ We have recently seen one patient found to have a carotid aneurysm and one with an abdominal aortic aneurysm, both of which were infected with salmonella, after they presented with relatively minor gastrointestinal symptoms. ${ }^{+}$Rather than causing thrombosis such infection leads to softening and a rapid enlarge ment of the aneurysm with an extremely high mortality unless a prompt diagnosis is made.

Any patient with septicaemia caused by salmonella and an aneurysm should, therefore, be presumed to have an infected aneurysm until proved otherwise and should be treated accordingly.

G STANSBY

K DAWSON

Royal Free Hospital School of Medicine, G HAMILTON

London NW3 2QG

1 Mosley JG, Chaudhuri AK. Surgery and salmonella. Br Med $\mathscr{X}$ 1990;300:552-3. (3 March )

2 Cohen JI, Bartlett JA, Corey GR. Extra-intestinal manifestation of salmonella infections. Medicine 1987;66:349-88.

3 Perry MO. Infected aortic aneurysms. F Vasc Surg 1985;2:597-9.

Stansby ( $\mathbf{r}$, Dawson K, Hamilton (i. Abdominal aortic salmonelosis presenting as an aorto-enteric fistula. Vascular Surgery in press

\section{Creating a new drug service in Edinburgh}

SIR, - We would dispute the impression created by Dr Judy Greenwood' that nothing useful is being done by medical practitioners outside Edinburgh to manage drug abuse and reduce consequent spread of HIV and that doctors who do not prescribe maintenance drugs are either old fashioned or recalcitrant and unwilling to listen to common sense.

Even before the arrival of HIV infection intravenous drug abuse had a high associated morbidity and mortality, and the "new service" that Dr Greenwood advocates was actually used extensively in Glasgow between 1968 and 1983. Eventually the impression was formed that more useful interventions could be made if street drugs were not on offer, and the clinic policy was changed 